\title{
Formation of Through Holes in Glass Substrates by Laser-Assisted Etching
}

\author{
Masatoshi Yonemura*1, Satoru Kato ${ }^{* 1}$, Kazuo Hasegawa*1 and Hidetomo Takahashi*2 \\ ${ }^{* 1}$ Toyota Central R\&D Labs., Inc. 41-1 Yokomichi, Nagakute, Aichi 480-1192, Japan \\ E-mail: yonemura@mosk.tytlabs.co.jp \\ ${ }^{* 2}$ Aisin Seiki Co., Ltd. 2-1 Asahi-machi, Kariya, Aichi 448-8650, Japan
}

\begin{abstract}
In this study, we worked on the formation of micro through holes in multi-component glass substrates using laser-assisted etching, in which mixed aqueous solutions of hydrofluoric acid (HF) and nitric acid $\left(\mathrm{HNO}_{3}\right)$ were used for the etching. Glass samples modified by femtosecond laser irradiation were immersed for 10 minutes in aqueous solutions containing 2\% HF and between 0 and $32 \%$ $\mathrm{HNO}_{3}$. The subsequent optical microscope observations and measurements showed that the highest etch selectivity, which was 21 , was obtained with an etch solution containing $6 \% \mathrm{HNO}_{3}$. Furthermore, through holes with diameters approaching $20 \mu \mathrm{m}$ were successfully formed in a $100 \mu \mathrm{m}$ thick glass substrate without any cracks using the mixed solution.
\end{abstract}

DOI: $10.2961 / \mathrm{j} \operatorname{lmn} .2016 .02 .0001$

Keywords: Femtosecond laser, laser-assisted etching, multi-component glass, through hole via, nitric acid

\section{Introduction}

Laser-assisted etching is a powerful method for forming three-dimensional (3D) microstructures in transparent materials. In this method, femtosecond laser irradiation of the material causes nonlinear absorption and modification of the material at the focal point. The modified region can be removed selectively by wet chemical etching, so that a microstructure is formed in the material [1-2]. Many different micro components, such as channels [1-12], mechanical elements [13-15], optical elements [16-19], sensors [20-21], lasers [22] and photonic crystals [23], have been formed using this method. One of the promising applications of these components is microfluidics for chemical and biological analysis [24-26].

We have been working on the formation of micro through holes in multi-component glass substrates using this method. Such through holes are needed for 3D semiconductor device packaging technologies where they are used as through glass vias (TGVs). These are generally required to be less than $20 \mu \mathrm{m}$ in diameter in 100 to 200 $\mu \mathrm{m}$ thick substrates. Other methods to form such holes, such as laser ablation [27-29], have been investigated; however, this has not become an established technique. For this study, we used mixed aqueous solutions of hydrofluoric acid (HF) and nitric acid $\left(\mathrm{HNO}_{3}\right)$ for the wet etching. It is commonly known that this mixed solution has a high etch rate as well as forming smooth surfaces in multi-component glass compared with using aqueous solutions containing $\mathrm{HF}$ only, because $\mathrm{HNO}_{3}$ prevents the precipitation of insoluble fluoride compounds [30]. On the other hand, the effect of the mixed solution in laserassisted etching is unknown. For this study, we investigated the relationship between the concentration of $\mathrm{HNO}_{3}$ in the mixed solution and the etch selectivity, which is defined as the etch depth of the modified region divided by the etch depth of the unmodified region. Furthermore, we demonstrated the formation of $20 \mu \mathrm{m}$ diameter through holes in a $100 \mu \mathrm{m}$ thick glass substrate using the mixed solution with the highest etch selectivity.

\section{Experiment}

Schematic illustrations of the glass sample modification process are presented in Fig.1. As shown in Fig. 1(a), an amplified femtosecond fiber laser system (IMRA America, FCPA $\mu$ Jewel), operating at a wavelength of $1045 \mathrm{~nm}$, with a $450 \mathrm{fs}$ pulse width and $100 \mathrm{kHz}$ repetition rate was used. The laser beam passes through an attenuator and a beam

(a)

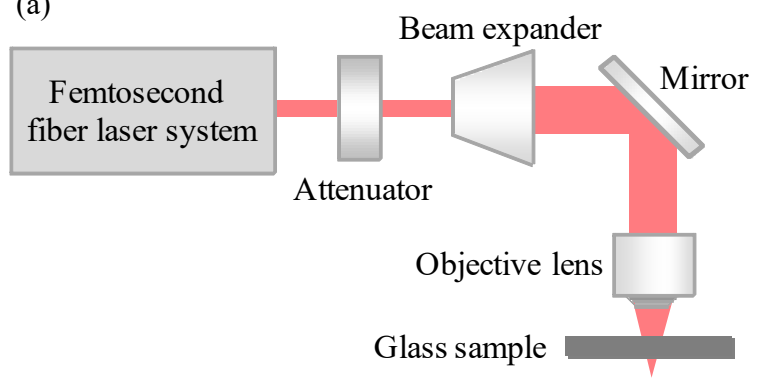

(b)

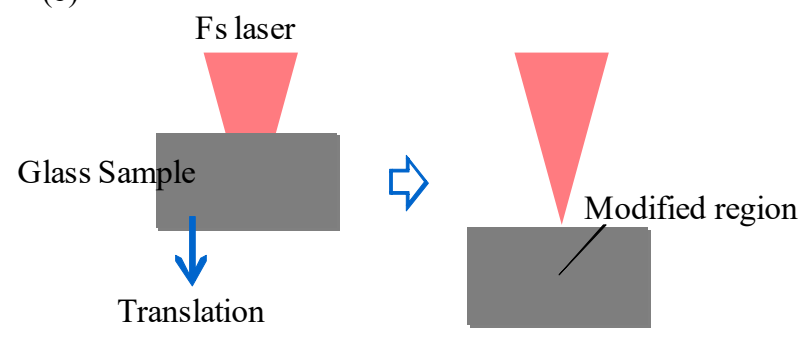

Fig. 1 Schematic illustrations of the glass sample modification process. (a) Experimental setup. (b) The glass sample is translated by a motorized stage, and a linear modified region is formed. 


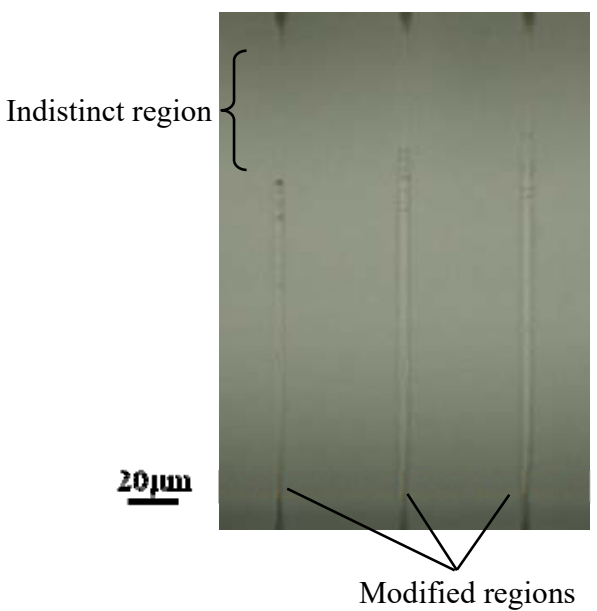

Fig. 2 Optical microscope image of the modified sample with three linear modified regions.

expander and is then focused by a $20 \times$ objective lens $(\mathrm{NA}=0.4)$. The pulse energy irradiated to the glass sample was adjusted to $1 \mu \mathrm{J} /$ pulse by the attenuator, which consists of a half-wave plate and a polarized beam splitter. The multi-component glass samples used in this experiment were non-alkaline glass with a thickness of $200 \mu \mathrm{m}$. These were mounted on a motorized stage and translated in the direction of the optical axis at a speed of $20 \mathrm{~mm} / \mathrm{s}$ such that the focal point moved from the rear surface to the front surface of the sample, thus forming a linear modified region as shown in Fig. 1(b). Fig. 2 is an optical microscope image of one of these samples, in which three modified regions can be seen. It is clear that the modified regions are not homogeneous along the optical axis; indistinct regions are found on the front side of the each modified region (upper side of the image). This inhomogeneity is probably caused by the influence of spherical aberration due to refractive indexmismatch at the interface between the glass and air [31]. These samples were immersed for 10 minutes at room temperature in aqueous solutions containing $2 \% \mathrm{HF}$ and between 0 and $32 \% \mathrm{HNO}_{3}$, which was varied for each sample. After etching, the samples were analyzed using an optical microscope.

\section{Results and discussion}

Fig. 3 shows optical microscope images of the etched samples, with the concentration of the $\mathrm{HNO}_{3}$ being (a) $0 \%$, (b) $3 \%$, (c) $6 \%$ and (d) $32 \%$ (by weight). The top and bottom of the images correspond to the front and rear surfaces of the samples, respectively. The images show that the hole depth on the front side differs from that on the rear side in all samples. On the front side, the hole depth is insufficient. The indistinct modified regions mentioned above have prevented the hole from extending deeper into the glass, which means that the etch rate of the indistinct regions are very low. From here on, we focus our attention only on the rear side of the samples. As shown in the images, the hole depth and shape depend on the $\mathrm{HNO}_{3}$ concentration. In particular, in the $32 \%$ sample, the hole diameter at the entrance is very large, and the sample has become thinner compared with the other samples. This is because the unmodified region of the glass is also etched well by the concentrated $\mathrm{HNO}_{3}$, so

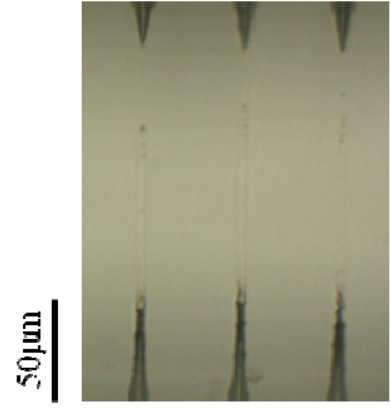

(a) $0 \%$

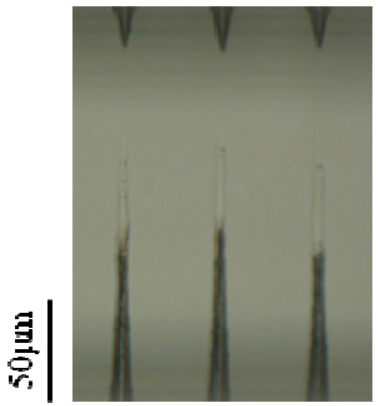

(c) $6 \%$

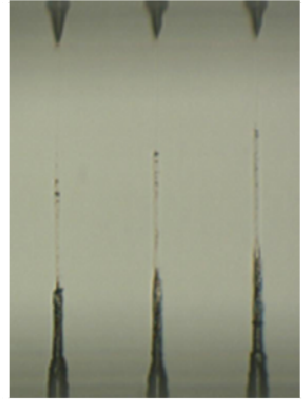

(b) $3 \%$

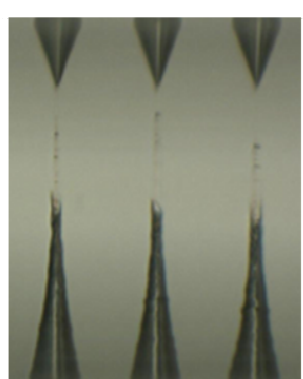

(d) $32 \%$
Fig. 3 Optical microscope images of the etched samples, with concentration of the $\mathrm{HNO}_{3}$ being (a) $0 \%$, (b) $3 \%$, (c) $6 \%$, (d) $32 \%$ (by weight).

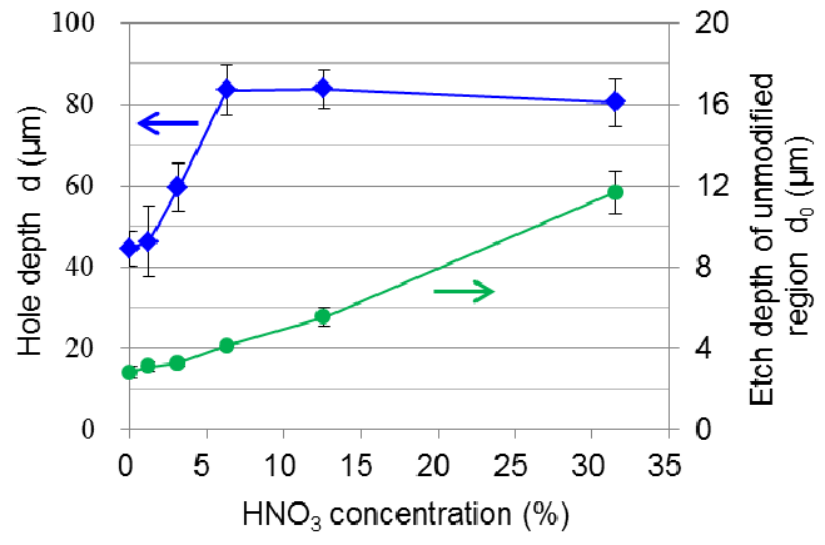

Fig. 4 Measurements of the hole depth (on the left-hand axis) and the etch depth of unmodified region (on the right-hand axis) as a function of $\mathrm{HNO}_{3}$ concentration.

the hole extends laterally over the modified region as well as thinning the sample. The measurements of the hole depth, d, from these images are summarized in Fig. 4 as a function of $\mathrm{HNO}_{3}$ concentration. The depth here is the average depth of 10 to 13 holes for each plotted value. Additionally, the error bars in the figure represent standard deviation $(1 \sigma)$. The etch depth of the unmodified region, $\mathrm{d}_{0}$, which is half the reduction in thickness of the sample, is also shown in the figure. As shown in the figure, $d$ increases rapidly as the concentration of $\mathrm{HNO}_{3}$ increases to $6 \%$. When it exceeds $6 \%$, d more or less saturates. This saturation can be explained as being due to fresh solution being unable to reach the bottoms of the holes as the hole depth 
increases [5]. On the other hand, the etch depth of the unmodified region, $\mathrm{d}_{0}$, increases monotonically as the concentration of $\mathrm{HNO}_{3}$ increases. Fig. 5 shows the etch selectivity, $\delta$, as a function of $\mathrm{HNO}_{3}$ concentration. $\delta$ is defined by the equation $\delta=\left(\mathrm{d}+\mathrm{d}_{0}\right) / \mathrm{d}_{0}$, which represents the etch depth of the modified region $\left(\mathrm{d}+\mathrm{d}_{0}\right)$ divided by the etch depth of the unmodified region $\left(\mathrm{d}_{0}\right)$. From the figure, the highest value of $\delta$, i.e. 21 , is observed with a $\mathrm{HNO}_{3}$ concentration of $6 \%$. The highest etch selectivity, 21 , is much lower than the etch selectivity of fused silica (more than a few hundred) $[5,6]$, because, unlike in fused silica, no periodic nanostructures are formed in multi-component glass such as non-alkaline glass [5].

We tried to form through holes in $100 \mu \mathrm{m}$ thick nonalkaline glass substrates using the mixed etching solution containing $6 \% \mathrm{HNO}_{3}$ and $2 \% \mathrm{HF}$. Optical microscope images of these through holes are shown in Fig.6. This shows cross-sections of the through holes in a cleaved sample. The holes have a pitch of $50 \mu \mathrm{m}$ and have been successfully formed without any cracks around them. The diameter of the holes is close to $20 \mu \mathrm{m}$; thus the aspect ratio is about 5 .

\section{Conclusion}

Laser-assisted etching, which uses femtosecond laser irradiation followed by wet chemical etching, is a powerful method for forming 3D microstructures. In this study, we used this method with mixed aqueous solutions of HF and $\mathrm{HNO}_{3}$ for the etching to form micro through holes in multicomponent glass substrates. The samples were modified by a femtosecond laser and subsequently immersed for 10 minutes in aqueous solutions containing 2\% $\mathrm{HF}$ and between 0 and $32 \% \mathrm{HNO}_{3}$. The subsequent optical microscope observations and measurements showed that the highest etch selectivity, 21, was observed with a $\mathrm{HNO}_{3}$ concentration of $6 \%$. Furthermore, through holes with diameters approaching $20 \mu \mathrm{m}$ were successfully formed in a $100 \mu \mathrm{m}$ thick glass substrate using the solution. Our plan for our future work is to reduce the inner wall roughness and the taper angle of the holes. For that, we need to reduce the inhomogeneity of the modified region. Additionally, material analysis of the modified region is also important. We believe that this is a potentially effective method for forming small diameter holes with narrow pitch compared with other methods.

\section{References}

[1] Y. Kondo, J. Qiu, T. Mitsuyu, K. Hirao and T. Yoko: Jpn. J. Appl. Phys., 38, (1999) L1146.

[2] A. Marcinkevičius, S. Juodkazis, M. Watanabe, M. Miwa, S. Matsuo, H. Misawa and J. Nishii: Opt. Lett., 26, (2001) 277

[3] Y. Bellouard, A. Said, M. Dugan and P. Bado: Opt. Express, 12, (2004) 2120.

[4] S. Juodkazis, K. Yamasaki, V. Mizeikis, S. Matsuo and H. Misawa: Appl. Phys. A, 79, (2004) 1549.

[5] C. Hnatovsky, R. S. Taylor, E. Simova, P. P. Rajeev, D. M. Rayner, V. R. Bhardwaj and P. B. Corkum: Appl. Phys. A, 84, (2006) 47.

[6] S. Kiyama, S. Matsuo, S. Hashimoto and Y. Morihira: J. Phys. Chem. C, 113, (2009) 11560.

[7] K. C. Vishnubhatla, N. Bellini, R. Ramponi, G. Cerullo and R. Osellame: Opt. Express, 17, (2009) 8685.

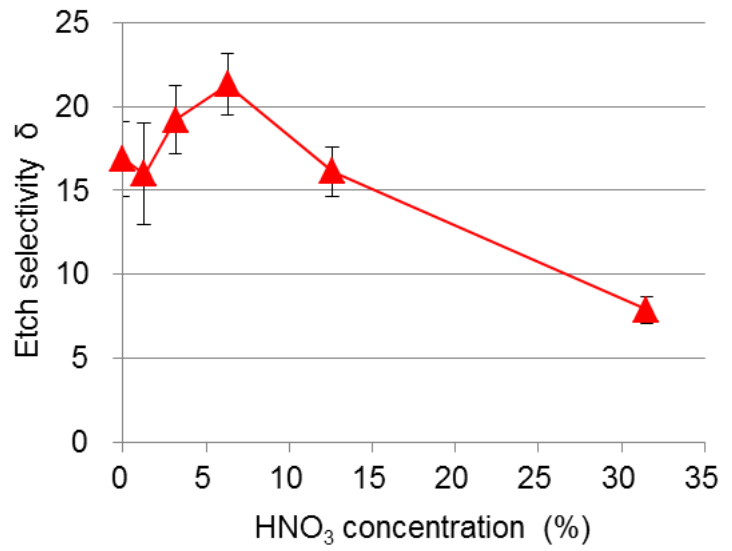

Fig. 5 Etch selectivity as a function of $\mathrm{HNO}_{3}$ concentration.

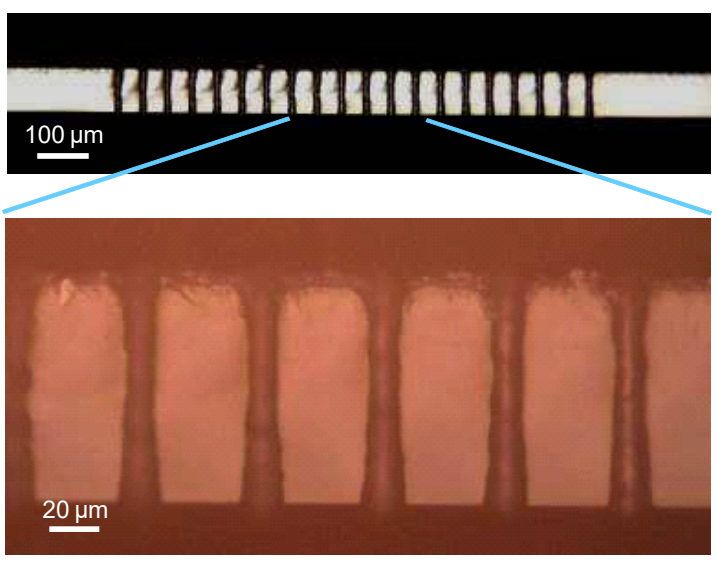

Fig. 6 Optical microscope images of the through holes in a $100 \mu \mathrm{m}$ thick non-alkaline glass substrate.

[8] X. Yu, Y. Liao, F. He, B. Zeng, Y. Cheng, Z. Xu, K. Sugioka and K. Midorikawa: J. of Appl. Phys., 109, (2011) 053114.

[9] S. He, F. Chen, K. Liu, Q. Yang, H. Liu, H. Bian, X. Meng, C. Shan, J. Si, Y. Zhao and X. Hou: Opt. Lett., 37, (2012) 3825.

[10] S. Ho, P. R. Herman and J. S. Aitchison: Appl. Phys. A, 106, (2012) 5 .

[11] Y. Liao, J. Song, E. Li, Y. Luo, Y. Shen, D. Chen, Y. Cheng, Z. Xu, K. Sugioka and K. Midorikawa: Lab Chip, 12, (2012) 746.

[12] M. Hermans, J. Gottmann and F. Riedel: JLMN, 9, (2014) 126.

[13] M. Masuda, K. Sugioka, Y. Cheng, T. Hongo, K. Shihoyama, H. Takai, I. Miyamoto and K. Midorikawa: Appl. Phys. A, 78, (2004) 1029.

[14] S. Matsuo, S. Kiyama, Y. Shichijo, T. Tomita, S. Hashimoto, Y. Hosokawa and H. Masuhara: Appl. Phys. Lett., 93, (2008) 051107.

[15] J. Gottmann, M. Hermans and J. Ortmann: JLMN, 8, (2013) 15.

[16] Y. Cheng, K. Sugioka, K. Midorikawa, M. Masuda, K. Toyoda, M. Kawachi and K. Shihoyama: Opt. Lett., 28, (2003) 1144 
[17] Y. Cheng, K. Sugioka and K. Midorikawa: Opt. Express, 13, (2005) 7225.

[18]F. Chen, Z. Deng, Q. Yang, H. Bian, G. Du, J. Si and X. Hou: Opt. Lett., 39, (2014) 606.

[19] J. Lin, S. Yu, Y. Ma, W. Fang, F. He, L. Qiao, L. Tong, Y. Cheng and Z. Xu: Opt. Express, 20, (2012) 10212.

[20] Y. Lai, K. Zhou, L. Zhang and I. Bennion: Opt. Lett., 31, (2006) 2559.

[21] Y. Bellouard, A. A. Said and P. Bado: Opt. Express, 13, (2005) 6635.

[22] Y. Cheng, K. Sugioka and K. Midorikawa: Opt. Lett., 29, (2004) 2007.

[23] S. Ho, M. Haque, P. R. Herman and J.S. Aitchison: Opt. Lett., 37, (2012) 1682.

[24]K. Sugioka and Y. Cheng: Lab Chip, 12, (2012) 3576.

[25] R. Osellame, H. J. W. M. Hoekstra, G. Cerullo and M. Pollnau: Laser Photonics Rev., 5, (2011) 442.
[26] B.-B. Xu, Y.-L. Zhang, H. Xia, W.-F. Dong, H. Ding and H.-B. Sun: Lab Chip, 13, (2013) 1677.

[27] R. Delmdahl and R. Paetzel: J. Microelectron. Packag. Soc., 21, (2014) 53.

[28] R. Nakamura, T. Katsura, S. Fujikawa, T. Magara, T. Inagawa, Y. Aono and H. Tokura: Proc. 6th Int. Congr. on Laser Advanced Materials Processing, Niigata, (2013) p.153.

[29] K. Tatsukoshi, M. Ono and S. Takahashi: Proc. 6th Int. Congr. on Laser Advanced Materials Processing, Niigata, (2013) p.156.

[30] T. Yabune, T. Sakurai and T. Ohmi: Technical Report of IEICE, SDM 2001-168, (2001-10). (in Japanese)

[31]A. Marcinkevičius, V. Mizeikis, S. Juodkazis, S. Matsuo and H. Misawa: Appl. Phys. A, 76, (2003) 257.

(Received: May 24, 2015, Accepted: March 2, 2016) 